\title{
O Uso das Tecnologias Digitais no Apoio a Construção do Conhecimento Matemático
}

\author{
Antonio Neres Oliveira', Magda Bercht ${ }^{2}$, Marcus Vinícius de Azevedo Basso ${ }^{2}$, \\ Allison Costa do Nascimento ${ }^{1}$ \\ ${ }^{1}$ Universidade Federal do Maranhão (UFMA), Imperatriz - MA - Brasil \\ ${ }^{2}$ Universidade Federal do Rio Grande do Sul (UFRGS), Porto Alegre - RS - Brasil \\ aneresoliveira@gmail.com, berchteinf.ufrgs.br, basso.marcus@gmail.com, \\ allison_nascimento@hotmail.com
}

\begin{abstract}
This study describes a teaching experience carried out in a primary school, which included a sample of 36 ninth graders, whose average age was 13.87 years. The work has an empirical research supported in actionresearch and quantitative research in order to investigate the role of digital technologies in the construction of mathematical knowledge. The theoretical framework that supported this work is grounded in Jean Piaget's ideas, in particular the reflective abstraction. Partial results showed the potential of digital technologies in the construction of mathematical knowledge, when mediated by a knowledge project.
\end{abstract}

Resumo. O presente estudo descreve uma experiência didática realizada numa escola de ensino fundamental, que contemplou uma amostra de 36 alunos do nono ano, cuja média de idade era de 13,87 anos. O trabalho fez uma investigação empírica apoiado na pesquisa-ação e na pesquisa quantitativa, com o propósito investigar o papel das tecnologias digitais na construção do conhecimento matemático. A fundamentação teórica que suportou esse trabalho é embasada nas ideias de Jean Piaget, em especial, a abstração reflexionante. Os resultados parciais mostraram o potencial das tecnologias digitais na construção do conhecimento matemático, quando mediado por um projeto de conhecimento.

\section{Introdução}

Piaget (2011) faz uma crítica às posições epistemológicas empiristas e inatistas, que segundo o mesmo, traz prejuízos para as atividades autênticas e criativas. Becker (2012) concebe o empirismo como uma pedagogia diretiva e explica que, nesse modelo, o professor é o centro do processo e detentor de todo o conhecimento. Segundo Neto (1998), o inatismo nota a criança com um cérebro fortemente estruturado com uma supervalorização as estruturas inatas.

Piaget (1995) em seu livro sobre abstração reflexionante, mostra-se otimista quanto ao uso do conhecimento descrito em seus trabalhos pelos educadores, mesmo advertindo sobre a natureza não pedagógica das suas obras. Segundo Becker (2012), pela abstração reflexionante é possível superar a metodologia de repetição, amplamente difundida nas unidades de ensino do país. O autor argumenta que esse tipo de metodologia reduz o sujeito à passividade. 
Segundo Piaget (1995), a abstração empírica está situada em nível do conhecimento físico quando se tira as qualidades ou ações do objeto alinhadas às suas características materiais. Já a abstração reflexionante, media o conhecimento lógico matemático apoiado no cognitivo do sujeito. Becker (2013) argumenta que pela abstração empírica, dos observáveis, retiram-se as qualidades dos objetos.

Becker (2013) resguarda que a abstração reflexionante parte de um pensamento reflexivo até níveis metareflexivos. Ainda, segundo esse autor, o processo vai se operando e vencendo etapas até chegar a um patamar superior, bem mais elaborada que a construção da fase anterior. Esse movimento, segundo Piaget (1995), desenvolve-se numa espiral contínua até atingir níveis gerais do conhecimento com a possibilidade de criação de novidades.

O projeto pedagógico tradicional se esforça para conter a disposição dos alunos ao manter a disciplina escolar. Nessa busca, furta a energia e expropria a capacidade de criação do ser. $\mathrm{O}$ espaço escolar, baseado na transmissão de conhecimentos, conspira contra os princípios da criatividade e deprime o processo de ensino e aprendizagem de Matemática. Freire (2011) usou a expressão "educação bancária" para explicar o que ocorre na maioria das escolas, no que diz respeito ao processo de transmissão de conhecimentos. $\mathrm{O}$ aluno funciona como um banco ao receber pequenos depósitos de conteúdo, uma espécie de poupança, para ao final de determinado período, devolver ao depositário com juros e correção monetária.

Ainda, no contexto educacional, Becker (2013) questiona por que apenas 2\% dos estudantes querem seguir a profissão de educador. Sua resposta, alicerçada numa pesquisa com educadores das escolas públicas de Porto Alegre-RS, aponta para a falta de práticas pedagógicas que transformem o ambiente escolar, em especial a sala de aula, em um espaço de invenção e criação. Segundo Piaget (1995), a fonte de novidades nasce da necessidade do equilíbrio entre a assimilação e acomodação, i.e, na eterna busca do equilíbrio cognitivo.

O estudo apresenta uma experiência didática sobre o uso das Tecnologias Digitais de Informação e Comunicação (TDIC), acoplado a um projeto de conhecimento, no sentido de proporcionar à educação, alternativas de construção do conhecimento matemático. O trabalho apresenta cinco seções. Na primeira e segunda seção são apresentadas as teorias que versam sobre a construção do conhecimento e da criatividade em Matemática. Na terceira, descreve-se a experiência, onde foram apresentados as particularidades da amostra e os desafios propostos numa experiência didática. Na quarta, são analisados os resultados da produção criativa dos alunos, nos aspectos da construção do conhecimento, segundo os princípios da abstração reflexionante e na última seção são apresentadas as conclusões.

\section{As Tecnologias Digitais no Apoio a Construção do Conhecimento Matemático}

Existem alguns trabalhos que teorizam e realizam ações concretas no sentido de mudanças no modelo atual da educação básica. Figueiredo, Nobre e Passos (2015) apontam algumas alternativas que primam pelo uso das tecnologias digitais. Já Vieira e Baptista (2015) concordam sobre esse ponto, entretanto advertem sobre a necessidade da inclusão dos projetos educacionais na gestão e uso das TDIC. 
Os autores Idris e Nor (2010) inferem sobre as possibilidades dos alunos visualizarem conceitos matemáticos de difícil compreensão, fazendo uso de software de construções dinâmicas. Nas aulas típicas desenvolvidas no plano do quadro negro ou branco, com giz ou pincéis, não é possível construir ilustrações claras e dinâmicas, como aquelas que poderiam ser desenvolvidas com ajuda da tecnologia.

Em relação a essa discussão, Paiva, Amado e Carreira (2014) argumentam que, em ambientes tecnológicos, os alunos são levados a refletir sobre as implicações matemáticas de suas ações, uma vez que abre uma gama de opções para experimentar novas ideias de tal maneira que seria impossível apenas com o uso de papel e lápis.

Türegün e Conde (2014), em suas conclusões preliminares sobre o papel da tecnologia e da criatividade no desenvolvimento da capacidade em resolver problemas, inferiram, a partir de um conjunto de respostas produzidas por um grupo de alunos, sobre a necessidade de proporcionar ambientes ricos e oportunos para o engajamento de professores a serviço de atividades criativas voltadas à resolução de problemas matemáticos.

Os professores podem idealizar, com ajuda de computadores e softwares de construções dinâmicas, desafios para promover a criatividade que, além de ganhar produtividade em relação aos métodos tradicionais, contribuem para compreensão e construção do conhecimento. Desse modo, o estudante pode criativamente animar, no plano ou no espaço os ângulos de um triângulo, a área, o perímetro e os lados de um polígono, assim como, também, observar suas relações simultaneamente [Idris e Nor 2010].

\section{A Experiência Didática}

A experiência, da presente análise, teve como foco uma escola de ensino fundamental do município de Imperatriz-MA, especificamente com 36 alunos do nono ano A, cuja média de idade era de 13,87 anos. O estudo contou com colaboração do professor da disciplina (matemático licenciado), um auxiliar de pesquisa (graduado em ciências naturais), a Coordenação Pedagógica, um mestre em história da arte, um técnico em informática, um especialista em Linux e o professor pesquisador.

A intervenção durou um semestre escolar, com início em agosto e término em dezembro de 2015, com frequência semanal. A turma foi dividida em comum acordo em dois grupos de 18 alunos e distribuídos em nove computadores. Os encontros tinham uma dinâmica de tal maneira que, o pesquisador e professor da disciplina se encontravam nas segundas-feiras e com os alunos nas quintas-feiras.

Os momentos com o professor da disciplina (segundas-feiras) eram discutidos as tarefas para fomentar o desenvolvimento dos alunos, alinhado aos problemas abertos e desafiadores. Nessas oportunidades, também se direcionaram questões relacionadas ao andamento do projeto. Nas atividades das quintas-feiras, metade da turma (grupo $\mathrm{A}_{1}$ ) dirigia-se ao laboratório de informática, enquanto a outra metade (grupo $\mathrm{A}_{2}$ ) permanecia aos cuidados do professor da disciplina. $\mathrm{O}$ grupo $\mathrm{A}_{1}$, realizava atividades do projeto de conhecimentos com apoio das TDIC; ao passo que o grupo $\mathrm{A}_{2}$, assistia às aulas diferenciadas com base em produções que primavam pela resolução, elaboração e redefinição de problemas. 
Além desses momentos, houve uma participação especial dos alunos em duas oficinas de artes. A primeira, discorreu sobre a construção e elaboração de logomarcas e logotipos. A segunda, proporcionou aos alunos uma viagem pela imaginação infantil, com a construção de brinquedos de infância do contexto dos discentes.

As atividades desenvolvidas, durante a realização do evento, foram registradas de diferentes maneiras: em expressão fotográfica, através de câmeras de celulares; pelas marcas da trajetória dos alunos no exercício das suas atividades; por meio dos protocolos de construção do GeoGebra e do programa de captura de tela Wink 2.0 versão Linux; nos relatórios de campo, naquilo que o pesquisador percebeu, ouviu, viu e experimentou e pensou. A pesquisa foi autorizada pela Secretaria Municipal de Educação (SEMED); pelos pais ou responsáveis dos alunos; pelos próprios alunos e pela Coordenação Pedagógica.

A escolha da metodologia por projetos de conhecimento justifica-se em termos, pela necessidade de envolver os alunos em atividades que priorizem a construção do conhecimento. Nessa perspectiva, fez-se uso dos fundamentos teóricos defendidos por Paulinho Filho, Nuñez e Ramalho (2004) que envolve o pensar, o agir e a reflexão construtiva.

O construto acoplou seletivamente uma ferramenta de construção matemática, o GeoGebra e os programas de produtividade nativos do Linux, além de duas oficinas de artes. Na realização de uma competência que envolve os saberes e vivências dos alunos e as demandas formais do conteúdo escolar, imaginou-se um projeto que congregassem tais variáveis. Nesse cenário, e segundo orientações de Paulinho Filho, Nuñez e Ramalho (2004), atendeu as situações significativas individuais, sociais e históricas.

Com olhar focado nesses princípios, o projeto foi concebido a partir uma situação-problema, que segundo Perrenoud (1999) deve colocar o aprendiz diante de uma série de decisões a serem tomadas para alcançar um objetivo. Nessa experiência, fez-se uso da competência que permite construir e planejar dispositivos e sequências didáticas para envolver o aluno em atividades de pesquisas, então para tal, foram apresentadas propostas associadas à realidade do discente e as demandas da disciplina.

Quanto às necessidades da disciplina, o conteúdo recaiu sobre a ideia de polígonos semelhantes, do Teorema de Pitágoras, da trigonometria no triângulo retângulo e do cálculo de áreas. No tocante à vivência, aos saberes e realidade ambiental dos alunos, foi criada uma sequência didática na qual solicitava aos alunos:

1) Concurso: para criação de uma logomarca usando apenas figuras geométricas planas;

2) A construção: de três pipas semelhantes (mesma forma) com auxílio do GeoGebra, cuja razão de semelhança era: 1 (pequena), 2 (média) e 3(grande);

3) Ao desafio: no que diz respeito à quantidade de papel utilizado para vestir o brinquedo, o que é mais vantajoso? Construir $1 / 4$ da pipa grande ou as pipas: pequena e média, respectivamente? (justifique) e, em relação ao perímetro, no tocante ao material utilizado para cerca a pipa? Vale mais a pena construir uma pipa grande ou as pipas: pequena e média, respectivamente? (justifique);

4) A proposta: crie problemas, com suas respectivas respostas, envolvendo o brinquedo e que esteja relacionado com sua área, o perímetro, à altura, aos ângulos; às semelhanças, razões, proporções e ao Teorema de Pitágoras. 
V Congresso Brasileiro de Informática na Educação (CBIE 2016)

Anais do XXII Workshop de Informática na Escola (WIE 2016)

\section{Análise da Experiência Didática}

Os resultados das atividades dos alunos que participaram da experiência didática produziram 35 diferentes logomarcas. A seguir, são apresentadas as produções que apresentaram maior nível de criatividade, segundo o julgamento de uma banca avaliadora. A Figura 1 mostra essas escolhas.

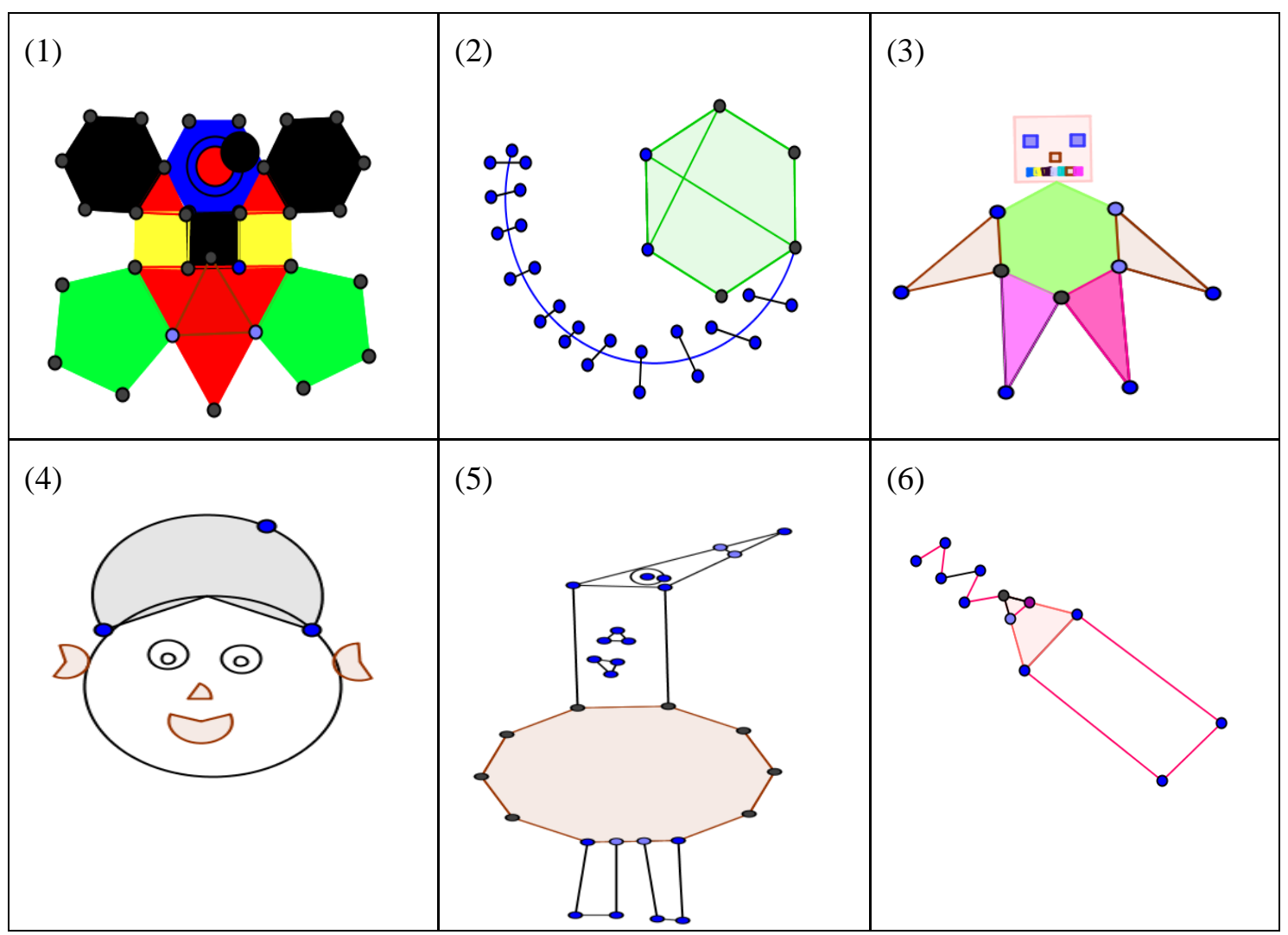

Figura 1. Destaque entre as logomarcas

As díades ao iniciarem os trabalhos não tinham experiência com GeoGebra e com os programas de produtividade do Linux, assim como também com o teclado convencional e próprio computador de mesa, apesar da vasta experiência com os aplicativos e os jogos eletrônicos. Esse fato mostra a necessidade de inclusão de projetos de conhecimento no processo de ensino e aprendizagem.

Ao final dessa primeira fase, a maioria absoluta conseguiu realizar suas atividades e operar satisfatoriamente com a ferramenta de construção dinâmica (GeoGebra) e com os aplicativos de produtividade, além de fazer uso do computador convencional.

O desafio proposto no projeto levou os alunos a manipular formas geométricas. Em [((1) o besouro)], usou-se hexágonos regulares, pentágono, círculos e circunferências, pontos, quadrados e triângulos equiláteros; O construto [(3) o robô] associou quatro triângulos a um hexágono, alguns retângulos e pontos para criar um robô. Nota-se nessas duas construções, uma abstração empírica, visto que não houve assimilação de novos conhecimentos, mas tão somente o uso ferramental do programa. 
O desenho [(6), apresenta um singelo lápis criado a partir da combinação de um retângulo, um triângulo, alguns pontos, ângulos e vários segmentos de retas. Segundo a díade, o desenho mostra um lápis ativo escrevendo a primeira letra do nome da turma (Mary + Ray_+). A construção (4) associa um semicírculo, três pontos, uma elipse, alguns arcos de círculos, circunferências concêntricas para formar um rosto gracioso de alegria, assim como em (5), deu-se asas à imaginação para criar um pássaro gordo desengonçado.

A criação (2) fez um apelo ao lúdico e ao imaginário infantil, então, articularamse os pontos, segmentos de retas, arco e circunferência, ângulos, triângulos quadriláteros, para fazer uma bela pipa. Diferentemente das construções anteriores, [(1) o besouro e (3) o robô], as criações (2), (4), (5) e (6) vão além do uso ferramental do programa, ao combinarem elementos distintos alinhados as noções geométricas. Nota-se nessa produção, uma reflexão acima do nível da abstração empírica, pois, novos elementos (noções, simetrias, alegria, gracioso, letras) externos ao objeto foram adicionados ao contexto. Fato típico da abstração reflexionante pseu-empírica.

A Figura 2 mostra um recorte dos resultados da criação e das respostas dos alunos, quanto ao problema de construir pipas semelhantes, a partir de uma informação inicial e da condição de semelhança dos brinquedos. A ideia dessa atividade foi levá-los um pouco mais adiante no processo de abstração reflexionante (da primeira fase do projeto). O professor pesquisador desafiou-os a criar um novo objeto (brinquedo do contexto) associado com sua área e seu perímetro, assim como, motivou-os a elaborar questões ao invés de respondê-las.

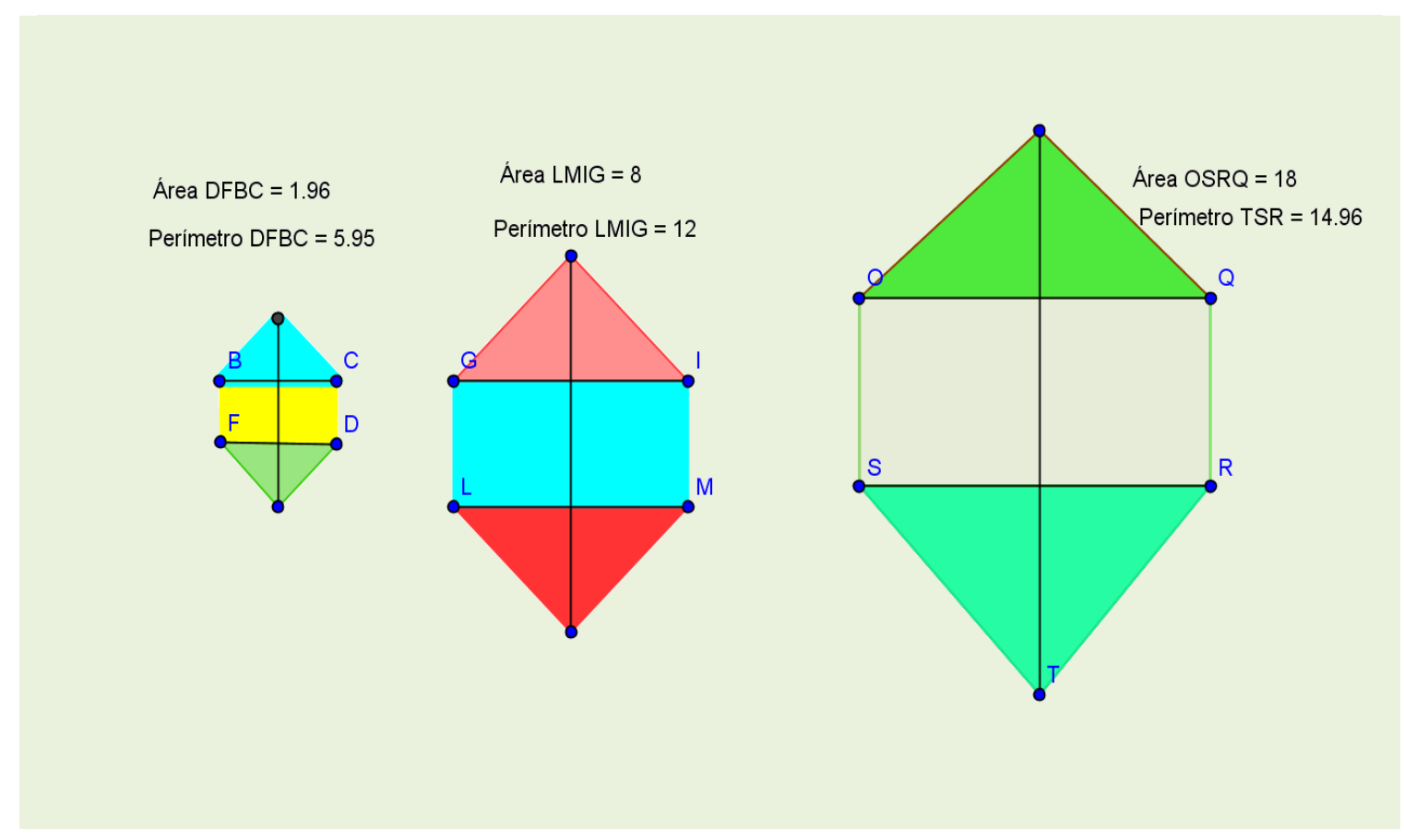


V Congresso Brasileiro de Informática na Educação (CBIE 2016)

Anais do XXII Workshop de Informática na Escola (WIE 2016)

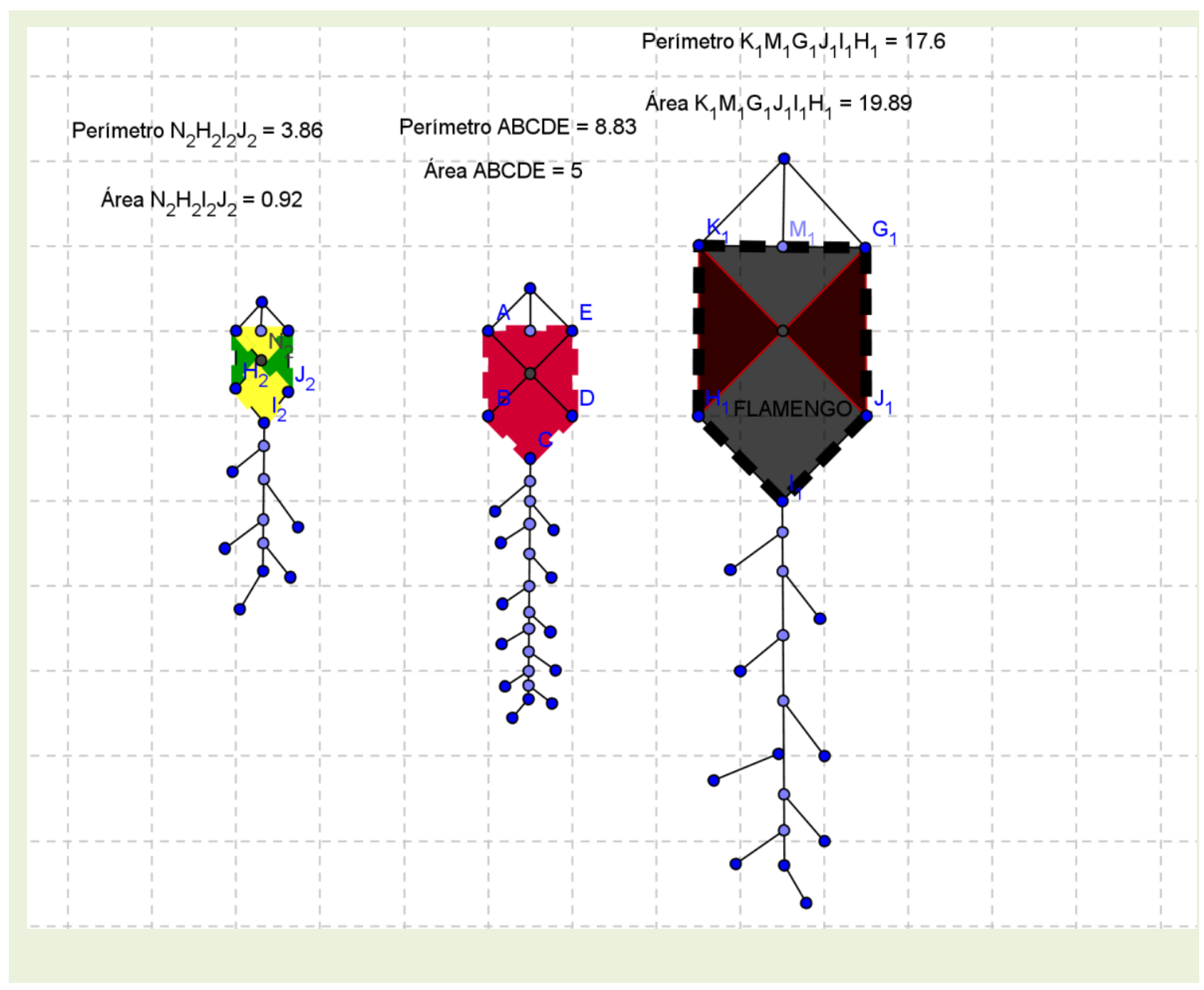

Figura 2. Destaque entre as pipas

O desafio impulsionou (as díades) a fazerem uma reflexão sobre a semelhança, o perímetro e a área das figuras planas, além da proposta da elaboração de problemas matemáticos, com base em suas construções e alinhadas aos conteúdos escolares.

O pesquisador manteve-se imparcial em relação à questão da colaboração, assumindo o risco e ônus dessa falta. Entretanto, apostou na capacidade dos alunos em recuperar informações nos meios digitais, no sentido de mobilizar conhecimentos. Não há como precisar o ganho quantitativo dessa escolha ativa, ou sua perda pela falta, entretanto, pelas evidências dos resultados quantitativos (apresentados na proficiência) alinhados as análises qualitativas, nos levaram à utopia de acreditar que é possível ensinar os conteúdos de Matemática apoiado pelas tecnologias digitais, numa perspectiva construtiva e com foco nas situações-problemas.

Não tem como precisar quanto desses experimentos impactaram as estruturas cognitivas, entretanto, Idris e Nor (2010); Fernandes e Pontes (2014) e Paiva, Amado e Carreira (2014) partilham que, em ambientes tecnológicos, os alunos são levados a refletir sobre as implicações matemáticas de suas ações. Ações e reflexões são a faísca e motor da construção do conhecimento, segundo os fundamentos da epistemologia genética. 
V Congresso Brasileiro de Informática na Educação (CBIE 2016)

Anais do XXII Workshop de Informática na Escola (WIE 2016)

\section{Resultados Quantitativos da Proficiência em Matemática}

A seguir, a Tabela 1 apresenta os resultados quantitativos de três avaliações realizadas com os alunos que participaram da experiência didática, no que diz respeito ao aproveitamento dos alunos na proficiência em Matemática - aspecto resolução de problemas e com base nas questões da prova Brasil.

Tabela 1. Resultados da proficiência em Matemática

\begin{tabular}{lccc}
\hline AVALIAÇÕES & Data & $\begin{array}{c}\text { Proficiência } \\
(\boldsymbol{\%})\end{array}$ & $\begin{array}{c}\text { Evolução } \\
(\boldsymbol{\%})\end{array}$ \\
\hline AV_01 & 05/fev & 30,88 & 1,78 \\
AV_02 & 05/ago & 32,66 & 3,37 \\
AV_03 & 02/dez & 36,03 & 5,15 \\
\hline
\end{tabular}

O grupo de alunos que participaram da experiência didática foi submetido a três proficiências, cujo objetivo era conhecer sua evolução antes e depois da experiência didática. Observa-se que, antes da intervenção o grupo evoluiu de 30,88 para 32,66 um incremento percentual de 1,78 . No período da intervenção, entre agosto e dezembro, o grupo variou de 32,66 para 36,03 - um acréscimo de 3,37 na proficiência. Os dados indicam que, houve um aumento na proficiência em Matemática na ordem de 1,59 por cento, entre os dois momentos pedagógicos. Entre a primeira $\left(\mathrm{AV}_{1}\right)$ e a última avaliação $\left(\mathrm{AV}_{3}\right)$, o grupo experimentou uma variação de 5,15, entretanto, nota-se que, aproximadamente $2 / 3$ desses valores pertencem ao período da experiência didática, i.e, a variação total de 5,15 ficou dividida por 1,78 (primeiro semestre) e 3,37 (segundo semestre), nas seguintes proporções: $34,56 \%\left(\frac{1,59}{5,15} * 100\right)$ e $65,44 \%\left(\frac{3,37}{5,15} * 100\right)$. No segundo semestre (período da experiência) houve um aumento na proficiência dos alunos de aproximadamente $30,88 \%(65,44$ - 34,56) em relação ao primeiro semestre (sem a experiência).

\section{Considerações Finais e Conclusão}

$\mathrm{O}$ ambiente institucional da escola moderado com o modelo tradicional e alinhado ao cronograma do projeto de ensino, ao calendário escolar e as preocupações com as avaliações bimestrais, impuseram restrições à dinâmica da experiência didática, no que diz respeito ao cronograma do projeto de conhecimento. O teste de proficiência em matemática também pode ter sido afetado pelo fator surpresa da prova, assim como pela impossibilidade de os alunos justificarem possíveis equívocos ou dúvidas. A proficiência abordou o mesmo assunto com questões diferentes, entretanto, os resultados no período da experiência conspiram a favor dos testes realizados no segundo semestre.

Agora, apesar das limitações, o estudo presta um serviço relevante para a educação matemática, que enfrenta grandes desafios nesse campo. As pesquisas demonstraram o potencial das TDIC na realização dos alunos na competência resolução de problemas. Uma das contribuições do estudo pode ser vislumbrada na possibilidade do uso das tecnologias digitais acoplados aos projetos de conhecimento como fomento à educação matemática. 
V Congresso Brasileiro de Informática na Educação (CBIE 2016)

Anais do XXII Workshop de Informática na Escola (WIE 2016)

Nesse aspecto, abre-se um campo de possibilidades para o novo, como a adoção de um livro digital; um sistema híbrido de aprendizagem, com consequente diminuição da importância do espaço físico; um currículo escolar próximo da realidade dos alunos e à luz das situações abertas e desafiadoras.

Os resultados também mostram o potencial das tecnologias digitais para promover a construção do conhecimento e a criatividade matemática. Então, seria preventivo transformar nossas salas de aulas em laboratórios, para criar espaços de construção e descobertas. Diante do exposto, conclui-se que, apesar das restrições, podem-se combinar racionalmente as tecnologias e as estratégias didáticas diferenciadas para promover a construção do conhecimento e a criatividade.

\section{Referências}

Becker, F. (2012). Epistemologia do professor de matemática.Petrópolis: Vozes.

Becker, F. (2013). "Sujeito do conhecimento e ensino de Matemática". Schème-Revista Eletrônica de Psicologia e Epistemologia Genéticas, 5, 65-86.

Fernandes, C. e Ponte, J. P. da (2014). "Using Statistical Software in Basic Education: difficulties and affordances". In: Proceedings of the Problem@Web International Conference: Technology, creativity and affect in mathematical problem solving, Portugal, 1, 35-46.

Figueiredo, G., Nobre, I. e Passos, M. L. S. (2015). "Tecnologias computacionais na educação: desafios na prática docente". In Anais do Workshop de Informática na Escola, Brasil, 21, 127-136.

Freire, P. (2011). Pedagogia do oprimido. 50. ed. Rio de Janeiro. Editora Paz e Terra.

Idris, N. e Nor, N. M. (2010). "Mathematical creativity: usage of technology". Procedia-Social and Behavioral Sciences, 2(2), 1963-1967.

Paulinho Filho, J., Nuñez, I. B. e Ramalho, B. L. (2004). "Ensino por projetos: uma alternativa para a construção de competência no aluno". In I. B. Nuñez e B. L. Ramalho. Fundamentos do ensino aprendizagem das Ciências Naturais e da Matemática: o novo Ensino Médio (pp. 265-283). Porto Alegre: Sulina.

Paiva, J., Amado, N. e Carreira, S. (2014). "The role of peer and computer feedback in student's problem solving". In: Proceedings of the Problem@Web International Conference: Technology, creativity and affect in mathematical problem solving, Portugal, 1, 59-70.

Perrenoud, P. (1999). Construir as Competências desde a escola. Porto Alegre: Artmed.

Piaget, J. (1995). Abstração reflexionante: relações lógico-aritméticas e ordem das relações espaciais. Porto Alegre: Artes Médicas.

Neto, E. R. (1998). Didática da matemática. São Paulo: Editora Ática.

Türegün, M. e Conde, L. (2014). "The Role of Using Technology and Creativity in developing positive dispositions toward mathematical problem solving".In: Proceedings of the Problem@Web International Conference: Technology, creativity and affect in mathematical problem solving, Portugal, 1, 108-119. 
V Congresso Brasileiro de Informática na Educação (CBIE 2016)

Anais do XXII Workshop de Informática na Escola (WIE 2016)

Vieira, M. e Baptista, B. (2015). "A utilização das Tecnologias da Informação e Comunicação nos projetos educacionais interdisciplinares". In Anais do Workshop de Informática na Escola, Brasil, 1, 197-206. 